\title{
Global trends and predictors of face mask usage during the COVID-19 pandemic
}

Elena Badillo-Goicoechea ${ }^{1 \dagger}$, Ting-Hsuan Chang ${ }^{2+}$, Esther Kim³ ${ }^{3}$, Sarah LaRocca ${ }^{3}$, Katherine Morris ${ }^{3}$, Xiaoyi Deng ${ }^{4}$, Samantha Chiu ${ }^{4}$, Adrianne Bradford ${ }^{4}$, Andres Garcia ${ }^{4}$, Christoph Kern ${ }^{5}$, Curtiss Cobb ${ }^{3}$, Frauke Kreuter ${ }^{4,6,7}$ and Elizabeth A. Stuart ${ }^{1,2^{*}}$

\begin{abstract}
Background: Guidelines and recommendations from public health authorities related to face masks have been essential in containing the COVID-19 pandemic. We assessed the prevalence and correlates of mask usage during the pandemic.

Methods: We examined a total of $13,723,810$ responses to a daily cross-sectional online survey in 38 countries of people who completed from April 23, 2020 to October 31, 2020 and reported having been in public at least once during the last 7 days. The outcome was individual face mask usage in public settings, and the predictors were country fixed effects, country-level mask policy stringency, calendar time, individual sociodemographic factors, and health prevention behaviors. Associations were modeled using survey-weighted multivariable logistic regression.

Results: Mask-wearing varied over time and across the 38 countries. While some countries consistently showed high prevalence throughout, in other countries mask usage increased gradually, and a few other countries remained at low prevalence. Controlling for time and country fixed effects, sociodemographic factors (older age, female gender, education, urbanicity) and stricter mask-related policies were significantly associated with higher mask usage in public settings. Crucially, social behaviors considered risky in the context of the pandemic (going out to large events, restaurants, shopping centers, and socializing outside of the household) were associated with lower mask use.

Conclusion: The decision to wear a face mask in public settings is significantly associated with sociodemographic factors, risky social behaviors, and mask policies. This has important implications for health prevention policies and messaging, including the potential need for more targeted policy and messaging design.
\end{abstract}

Keywords: COVID-19, SARS-CoV-2, Face mask, Mask usage

\footnotetext{
* Correspondence: estuart@jhu.edu

${ }^{\dagger}$ Elena Badillo-Goicoechea and Ting-Hsuan Chang contributed equally as first authors.

'Department of Mental Health, Johns Hopkins Bloomberg School of Public Health, 615 N. Wolfe St. W1033, Baltimore, MD 21205, USA

${ }^{2}$ Department of Biostatistics, Johns Hopkins Bloomberg School of Public Health, 615 N. Wolfe St. W1033, Baltimore, MD 21205, USA

Full list of author information is available at the end of the article
}

(c) The Author(s). 2021 Open Access This article is licensed under a Creative Commons Attribution 4.0 International License, which permits use, sharing, adaptation, distribution and reproduction in any medium or format, as long as you give appropriate credit to the original author(s) and the source, provide a link to the Creative Commons licence, and indicate if changes were made. The images or other third party material in this article are included in the article's Creative Commons licence, unless indicated otherwise in a credit line to the material. If material is not included in the article's Creative Commons licence and your intended use is not permitted by statutory regulation or exceeds the permitted use, you will need to obtain permission directly from the copyright holder. To view a copy of this licence, visit http://creativecommons.org/licenses/by/4.0/. The Creative Commons Public Domain Dedication waiver (http://creativecommons.org/publicdomain/zero/1.0/) applies to the data made available in this article, unless otherwise stated in a credit line to the data. 


\section{Background}

In an effort to control and prevent the spread of the novel coronavirus disease 2019 (COVID-19), health organizations have recommended the use of a face covering or mask in public settings. Yet, despite growing evidence of the effectiveness of using face masks in reducing the transmission of COVID-19 [1-7], there is still a lack of knowledge regarding mask-wearing behaviors on a global scale. In particular, it is still unclear how maskwearing behavior has changed over time, how trends have varied across countries throughout this pandemic, and whether individual or country-level factors are associated with mask-wearing. These questions are critical to better understand and target behaviors that are considered risky in the context of the pandemic, across different individuals and regions; clarify and fine-tune public health messaging around face mask usage during the pandemic, and, more generally, help better design prevention campaigns in future public health emergencies.

To this date, few studies have rigorously examined global trends and individual predictors of face mask usage during the COVID-19 pandemic, primarily simply documenting rates of mask usage [6-8]. Previous work has examined sociodemographic factors and individual beliefs and attitudes as predictors of mask-wearing during other health emergencies [9], such as SARS-Cov-1 and H1N1 [10-14]. In addition, most previous studies used small non-random samples (e.g., $\sim 300-5000$ selfselected participants), from which it is difficult to learn about mask usage on a general population scale. Previous studies also generally had a limited time frame (e.g., one or two months), and/or narrow geographical coverage (e.g., one or only a few countries). Further, most did not conduct statistical analyses that jointly examined individual-and country-level factors that may explain differences in mask-wearing behavior.

In general, better understanding the social and regional determinants of behavioral patterns is crucial to adequately adapt health policies and communication campaigns to diverse populations and make them more effective at reaching intended audiences considering their different contexts and needs $[15,16]$. Taking this into account is of utmost importance for the design of public health responses in the context of the ongoing global pandemic, such as those related to face mask usage and lockdown measures, which ultimately address-in most cases- individual decisions that might be influenced by social, political, and economic environments.

The main objective of this study was, therefore, to examine the evolution of mask usage across different countries over time during the COVID-19 pandemic and assess whether individual and country-level factors were associated with the decision to wear a mask. For this, we leveraged a novel dataset from the University of Maryland Social Data Science Center COVID-19 Trends and Impact Survey (CTIS) [17], conducted in partnership with Facebook, which has tracked mask usage, sociodemographic characteristics, health indicators, and health prevention behaviors on a daily basis since April 2020. To the best of our knowledge, the CTIS is currently the largest data collection effort systematically monitoring mask usage and other social responses to the ongoing COVID-19 pandemic at a global scale with representativeness at a country-level. We used data from respondents from 38 countries who were randomly selected to take this survey between April 23, 2020 to October 31, 2020 and who reported having been in public at least once during the last 7 days, which yielded approximately 13 million adults. To this date, no other study has used data with such characteristics to formally examine trends and predictors of mask usage worldwide.

\section{Methods}

The global COVID-19 trends and impact survey

The CTIS is an ongoing repeated daily cross-sectional survey conducted by the University of Maryland (Global) and Carnegie Mellon University (US) in partnership with Facebook, Inc. It asks various questions related to symptoms, testing, preventive behaviors, mental health, and more. The UMD Global CTIS was launched on April 23, 2020 in $>200$ countries and territories (Supplementary Table 1) and the US CTIS was launched on April 6, 2020. The survey instrument, sampling design, and weighting methodology are described in more detail below. The Symptom Survey was reviewed and approved by the Institutional Review Boards of both the University of Maryland and Carnegie Mellon University.

The survey instrument was developed by public health and survey experts [15], and included the following sections: COVID-19 related symptoms, testing, contact history, preventive behavior (e.g., face mask usage, hand washing, social distancing, etc.), mental health, economic security, and basic demographics. The questionnaire is publicly available online $[18,19]$, and is translated into 56 locales (listed in Supplementary Table 1).

The sampling methodology for the CTIS has been described previously [20]. Briefly, the sampling frame is composed of daily active Facebook users who are $>=18$ years, living within $200+$ countries or territories, and using one of the supported languages. This coverage ensures that $>95 \%$ of Facebook users are eligible. Every day, Facebook invites a stratified random sample to take the survey with an invitation at the top of their Facebook News Feed, with the sampling strata defined as the administrative boundaries within countries or territories [21]. Those who view the invitation and are interested in taking the survey are redirected to an off-Facebook 
survey administered by the academic partners. Facebook does not share or receive data from the academic partners other than a list of random identification numbers of those who completed the survey to calculate and share survey weights.

The details of the weighting methodology have been described previously [20]. Briefly, Facebook employs a two-stage weighting process to minimize bias related to non-response and coverage. In the first step, inverse propensity score weighting is used to adjust for nonresponse bias by making the sample more representative of the sampling frame of Facebook users. As stated above, Facebook only receives a list of identification numbers that indicate who completed the survey; therefore, the covariates used in this step are obtained from internal Facebook data, which consist of self-reported age, gender, geographical variables, and other attributes that have been found internally to correlate well with survey response [22]. At the second stage poststratification or raking is used to equate the distribution of age and gender among the Facebook population to benchmarks from the United Nations Population Division 2019 World Population Projections, and first administrative level region benchmarks from publicly available population density maps [23].

\section{Study population}

This analysis included adult participants who responded to the UMD Global CTIS from April 23rd, 2020 until October 31st, 2020. We did not include responses from the US Symptom Survey in this analysis, as the question on face mask usage was not incorporated into the US questionnaire until September 2020. Since some of the $200+$ countries and territories have relatively small sample sizes, with high variability in responses, we focused on 38 countries based on the following criteria: countries that are considered either members, candidates, or key partners of the Organisation for Economic Co-operation and Development (OECD) convention [24], or countries with a sample size $>600,000$ during our study period (Table 1). Over the course of field collection in the selected 38 countries, 741,496,298 Facebook users saw the survey invitation; 36,525,312 opened the survey invitation; and 18,730,575 responded to the survey. Of those, $1,020,188$ reported being in public in the past 7 days. Missingness on the predictors ranged from 2 to $13 \%$ per variable, which overall resulted in $27 \%$ of the survey respondents being excluded, leading to a final analysis sample of $13,723,810$.

\section{Outcome variable definition}

Our outcome was face mask usage, based on the survey question: "In the last 7 days, how often did you wear a mask when in public?" The response options were "All of the time", "Most of the time", "Some of the time", "A little of the time", "None of the time", or "I have not been in public during the past 7 days". We defined face mask usage as a binary variable: 1 if the respondent reported wearing a mask all or most of the time, and 0 otherwise.

\section{Predictor measurement}

We included several individual and country-level factors that could be associated with face mask usage based on a priori hypotheses and existing literature. Individuallevel predictors included age, gender, standardized years of education, urbanicity (defined as living in a city versus town, village, or rural area), and the following reported social behaviors from the last $24 \mathrm{~h}$ : working outside the household, going to a market/grocery store/pharmacy, going to a restaurant/cafe/shopping center, spending time with someone outside their household, and attending a public event with more than 10 people. We also included whether the respondent reported ever being tested for COVID-19, and two variables capturing individual economic aspects: worried about household finances and worked in the last 7 days. The three variables on years of education, financial worry, and employment status in the last 7 days were added to the survey on June 27, 2020; therefore, data on these items were not available earlier than this date.

Country-level predictors were country fixed effects, the (time-varying) presence of official policies related to face masks, and the (time-varying) incidence of COVID19 disease. The country-level mask usage policies were obtained from the University of Oxford Our World in Data's COVID-19 dataset, which contains daily countrylevel policies on the use of face coverings outside-of-thehome. The policies are graded from 0 to 5 and reflect the strength of the policy (i.e., no policy, recommended, required in some specified places, required in all shared/ public spaces, required at all times) for each country [25]. We generated standardized weekly averages of this mask-wearing policy stringency index for each country, and included the index as a continuous variable in the model. Country-day-level COVID-19 cases were obtained from the Johns Hopkins University Center for Systems Science and Engineering's repository [26], which we used as a standardized seven-day lagged average to measure the association between the rate of COVID-19 cases during the last 7 days and the individual's decision to wear a mask.

\section{Statistical analysis}

In addition to examining descriptive statistics, a surveyweighted multivariable logistic regression model was used to formally assess whether individual and countrylevel factors were associated with mask-wearing. All 
Table 1 List of countries included in the analysis

\begin{tabular}{|c|c|c|c|}
\hline \multirow[t]{2}{*}{ Country } & \multirow{2}{*}{$\begin{array}{l}\text { Total responses } \\
18,730,575(100 \%)\end{array}$} & \multirow{2}{*}{$\begin{array}{l}\text { Complete responses }^{\mathrm{a}} \\
14,552,118(77.69 \%)\end{array}$} & \multirow{2}{*}{$\begin{array}{l}\text { Analytic sample }^{\text {b }} \\
13,723,810(73.27 \%\end{array}$} \\
\hline & & & \\
\hline Argentina & $659,009(3.52 \%)$ & $484,352(2.59 \%)$ & $435,134(2.32 \%)$ \\
\hline Australia & 325,885 (1.74\%) & $266,113(1.42 \%)$ & $254,095(1.36 \%)$ \\
\hline Austria & $138,777(0.74 \%)$ & $113,097(0.6 \%)$ & $111,133(0.59 \%)$ \\
\hline Belgium & $142,999(0.76 \%)$ & $101,548(0.54 \%)$ & $97,550(0.52 \%)$ \\
\hline Brazil & $2,322,508(12.4 \%)$ & $1,788,903(9.55 \%)$ & $1,700,210(9.08 \%)$ \\
\hline Bulgaria & 96,459 (0.51\%) & $75,085(0.4 \%)$ & 72,191 (0.39\%) \\
\hline Canada & $417,071(2.23 \%)$ & $346,718(1.85 \%)$ & $329,517(1.76 \%)$ \\
\hline Chile & 324,447 (1.73\%) & 256,195 (1.37\%) & $229,449(1.22 \%)$ \\
\hline Colombia & $574,169(3.07 \%)$ & $449,043(2.4 \%)$ & $394,540(2.11 \%)$ \\
\hline Costa Rica & $167,986(0.9 \%)$ & $131,144(0.7 \%)$ & 115,907 (0.62\%) \\
\hline Czech Republic & $213,108(1.14 \%)$ & 168,216 (0.9\%) & $162,533(0.87 \%)$ \\
\hline Denmark & $306,917(1.64 \%)$ & $257,938(1.38 \%)$ & $254,406(1.36 \%)$ \\
\hline Finland & $157,593(0.84 \%)$ & $133,380(0.71 \%)$ & $125,433(0.67 \%)$ \\
\hline France & 708,994 (3.79\%) & $459,218(2.54 \%)$ & $442,412(2.36 \%)$ \\
\hline Germany & $763,760(4.08 \%)$ & $628,053(3.35 \%)$ & 619,066 (3.31\%) \\
\hline Greece & $197,813(1.06 \%)$ & $163,753(0.87 \%)$ & $154,268(0.82 \%)$ \\
\hline Hungary & $320,668(1.71 \%)$ & $255,230(1.36 \%)$ & $242,901(1.3 \%)$ \\
\hline India & $1,083,384(5.78 \%)$ & 728,852 (3.89\%) & $642,297(3.43 \%)$ \\
\hline Indonesia & 547,797 (2.92\%) & 398,395 (2.13\%) & 370,107 (1.98\%) \\
\hline Ireland & $163,006(0.87 \%)$ & $131,488(0.7 \%)$ & $125,645(0.67 \%)$ \\
\hline Israel & $193,693(1.03 \%)$ & $156,551(0.84 \%)$ & $150,858(0.81 \%)$ \\
\hline Italy & 989,919 (5.29\%) & 796,122 (4.25\%) & $775,840(4.14 \%)$ \\
\hline Japan & $1,418,201(7.57 \%)$ & $1,178,538(6.29 \%)$ & $1,163,828$ (6.21\%) \\
\hline Mexico & $1,831,010(9.78 \%)$ & $1,425,019(7.61 \%)$ & $1,302,477$ (6.95\%) \\
\hline Netherlands & $355,421(1.9 \%)$ & $294,844(1.57 \%)$ & $265,162(1.42 \%)$ \\
\hline New Zealand & $125,601(0.67 \%)$ & $101,695(0.54 \%)$ & $96,472(0.52 \%)$ \\
\hline Norway & $205,460(1.1 \%)$ & $171,999(0.92 \%)$ & $157,285(0.84 \%)$ \\
\hline Poland & $388,553(2.07 \%)$ & $265,143(1.42 \%)$ & 257,927 (1.38\%) \\
\hline Portugal & $353,606(1.89 \%)$ & $247,065(1.32 \%)$ & $238,697(1.27 \%)$ \\
\hline Romania & $385,949(2.06 \%)$ & $308,116(1.64 \%)$ & $293,426(1.57 \%)$ \\
\hline Russia & $273,870(1.46 \%)$ & 214,795 (1.15\%) & $201,447(1.08 \%)$ \\
\hline Slovenia & $43,665(0.23 \%)$ & $35,613(0.19 \%)$ & $34,606(0.18 \%)$ \\
\hline South Africa & 235,188 (1.26\%) & $189,818(1.01 \%)$ & $179,337(0.96 \%)$ \\
\hline Spain & $659,951(3.52 \%)$ & $518,427(2.77 \%)$ & 503,994 (2.69\%) \\
\hline Sweden & $484,930(2.59 \%)$ & $409,192(2.18 \%)$ & $385,530(2.06 \%)$ \\
\hline Switzerland & $148,638(0.79 \%)$ & $115,230(0.62 \%)$ & $112,087(0.6 \%)$ \\
\hline Turkey & $480,588(2.57 \%)$ & $359,907(1.92 \%)$ & $336,594(1.8 \%)$ \\
\hline United Kingdom & $523,982(2.8 \%)$ & $427,323(2.28 \%)$ & $389,449(2.08 \%)$ \\
\hline
\end{tabular}

${ }^{\mathrm{a}}$ Full sample for the primary model (April 23, 2020 - October 31, 2020)

${ }^{\mathrm{b}}$ Complete cases (analytic sample) included in the primary model (April 23, 2020 - October 31, 2020)

statistical analyses were performed in R (version 4.0.3), using the $\mathrm{R}$ survey package (version 4.0) to account for the sampling design. We estimated two separate models to accommodate the fact that the three questions capturing socioeconomic factors (financial worry, years of education, and employment status in the last 7 days) were added later in field collection. The primary model included the entire sample from April 23, 2020, through 
October 31, 2020, with all predictors described above except for the three not available before June 27, 2020. A secondary model was fit with a narrower time period spanning from June 27, 2020 until October 31, 2020, to include the additional three socioeconomic factors. We included month as a categorical variable in all models.

\section{Results}

Evolution of mask usage over time

Trends over time across the 38 countries (Fig. 1) suggested considerable heterogeneity in self-reported maskwearing in public across countries. Some countries had consistently high mask usage ( $>75 \%)$ from April until October (ex: Chile, Italy, Japan, Argentina, Colombia,
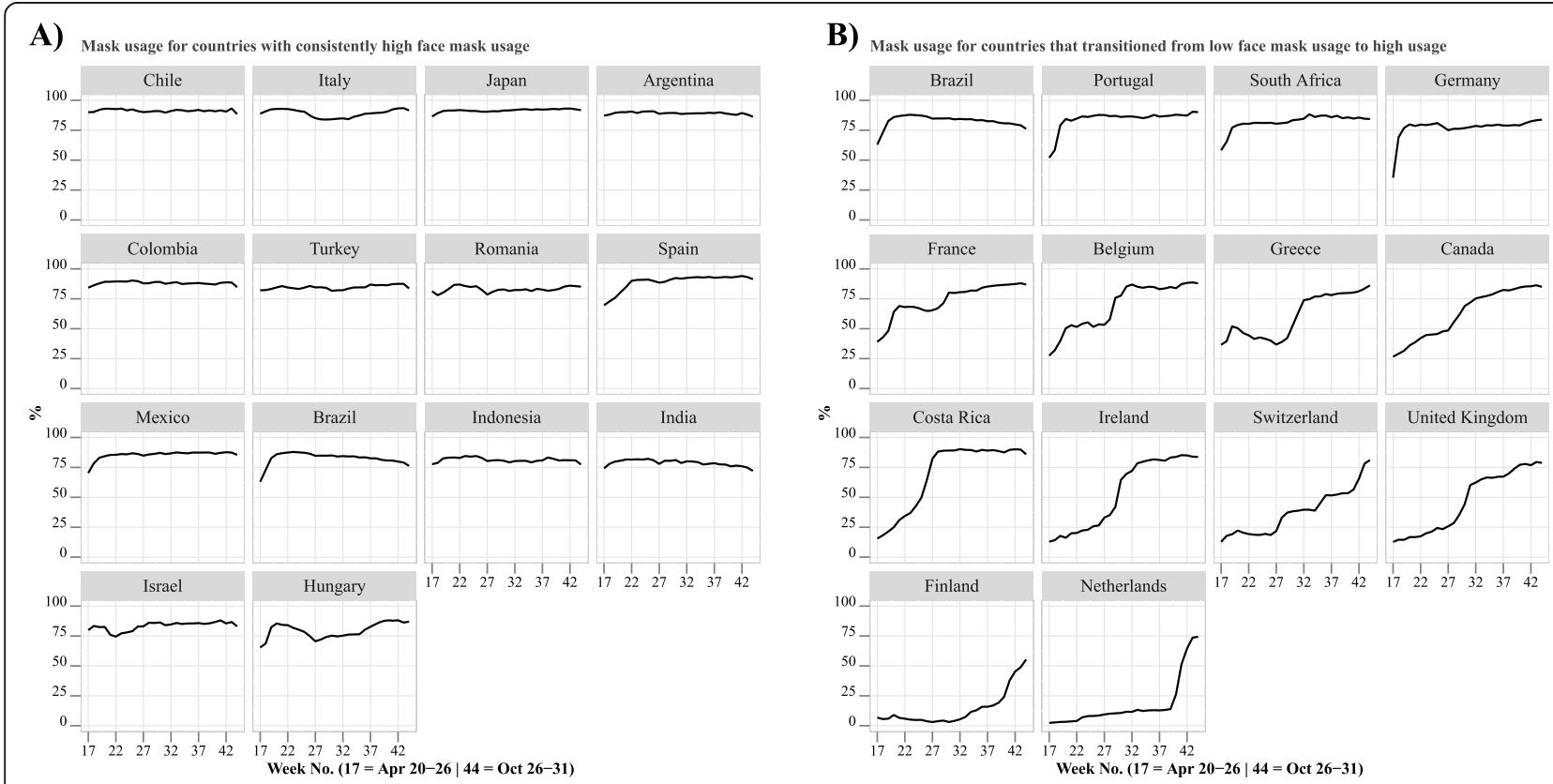

D)

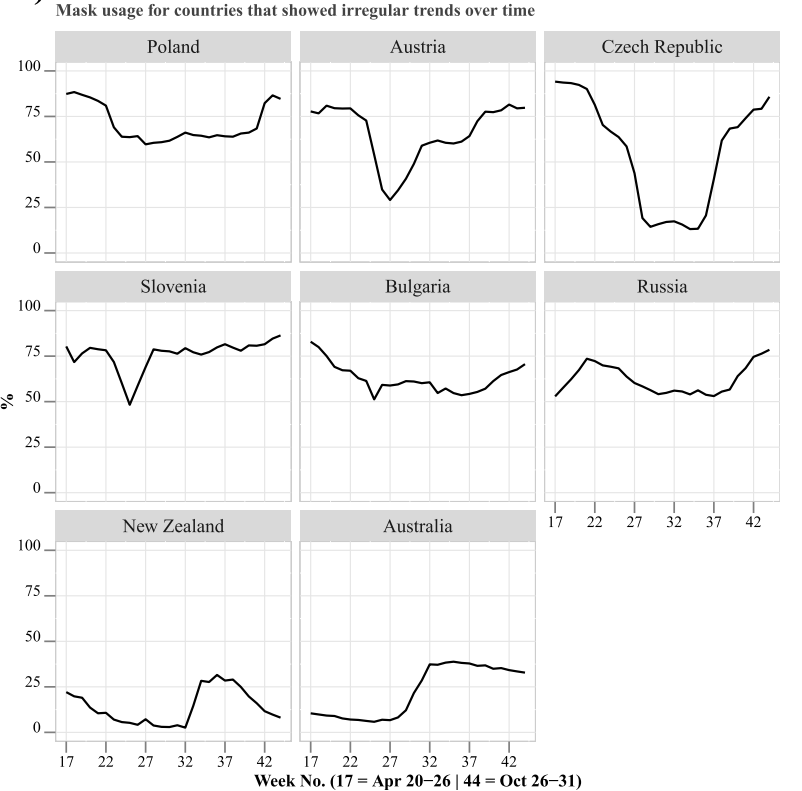

C) Mask usage for countries that had consistently low face mask usage

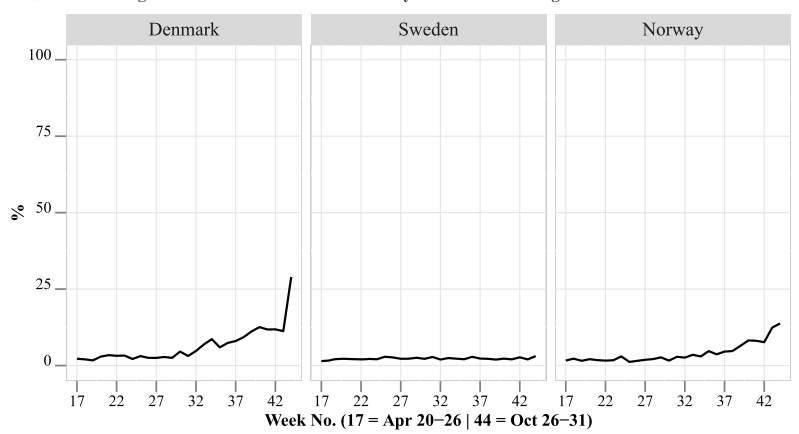

Week No. $(17=$ Apr 20-26 $\mid 44=$ Oct 26-31)

Fig. 1 Weighted self-reported weekly mask usage prevalence by country, (Weights adjust each country sample to their corresponding national population.) grouped by A) countries with consistently high face mask usage, B) countries that transitioned from low to high face mask usage, C) countries that had consistently low face mask usage, D) countries that showed irregular trends over time. Panel 1A) Mask usage for countries with consistently high face mask usage. Panel 1B) Mask usage for countries that transitioned from low face mask usage to high usage. Panel 1C) Mask usage for countries that had consistently low face mask usage. Panel 1D) Mask usage for countries that showed irregular trends over time 
Turkey, Romania, etc.) (Fig. 1A). In some other countries, mask usage was relatively low in April, but eventually increased and remained at higher levels (ex: Brazil, Portugal, South Africa, Germany, France, Belgium, Greece, Canada, etc.) (Fig. 1B). Mask usage was consistently low $(<25 \%)$ in certain countries (ex: Denmark, Sweden, and Norway) (Fig. 1C), and was more irregular in others (ex: Austria, Czech Republic, Slovenia, etc.) (Fig. 1D).

\section{Predictors of mask usage}

Results from the logistic regression model confirmed the observed cross-country mask-wearing trends over time, with individuals from the vast majority of countries particularly of Northern Europe - being significantly less likely to wear a mask when in public than individuals in Japan (the referent country). Individuals were more likely to wear a mask in later months (May: OR 1.71, 95\% CI [1.69, 1.75]; June: OR 1.95, 95\% CI [1.92, 1.99]; July: OR 2.01, 95\% CI [1.97, 2.05]; August: OR 2.60, 95\% CI $[2.55,2.65]$; September: OR 2.74, 95\% CI [2.69, 2.80]; October: OR 3.40, 95\% CI [3.32, 3.48]) (Table 2).

Demographic, behavioral, and policy-related factors were significantly associated with wearing a face mask in public, even after controlling for time and country fixed effects. Of the demographic factors, female gender (OR $1.70,95 \%$ CI $[1.69,1.71])$, living in an urban area (OR $1.40,95 \%$ CI $[1.39,1.41])$, and older age (age 25-34: OR 1.22 , 95\% CI $[1.20,1.23]$; age $35-44$ : OR $1.34,95 \%$ CI $[1.32,1.36]$; age $45-54$ : OR 1.43 , 95\% CI $[1.41,1.45]$; age 55-64: OR 1.42, 95\% CI [1.40, 1.44]); age 65+: OR 1.47, $95 \%$ CI $[1.45,1.49])$ were positively associated with wearing a face mask.

Of the behavioral factors, going to a market, grocery store, or pharmacy was associated with higher mask use (OR 1.07, 95\% CI [1.06, 1.08]), whereas more optional or risky behaviors [22] were associated with lower mask use. More specifically, behaviors associated with lower mask use were attending large public events (OR $0.45,95 \%$ CI $[0.44,0.45]$ ), socializing outside of the home [OR $0.72,95 \%$ CI [0.72, 0.73]), and going to a restaurant, cafe, or shopping center (OR 0.77, 95\% CI [0.77, 0.78]). Other significant behavioral factors examined were working outside from home, which was associated with lower mask usage (OR 0.98, 95\% CI [0.97, 0.99]), and having been tested for COVID-19, which was associated with higher mask use (OR 1.59, 95\% CI [1.57, 1.61]).

Regarding country-level factors, we observed that more strict policies were associated with higher mask usage (OR 1.58, 95\% CI [1.57, 1.59]), while lagged COVID-19 cases were (OR 0.93, 95\% CI [0.92, 0.94]) associated with less mask-wearing.
In the secondary model, which included data from late-June onwards and the three additional socioeconomic variables (financial worry, years of education, and employment status in the last 7 days), the aforementioned demographic, behavioral, and policy-related factors remained significantly associated with face mask usage. The three additional socioeconomic variables were significantly associated with mask-wearing: higher years of education was associated with higher use (OR $1.07,95 \% \mathrm{CI}[1.07,1.08]$ ) while financial worry and working in the last 7 days were associated with lower use (financial worry: OR $0.88,95 \% \mathrm{CI}[0.87,0.89]$; being employed in the last 7 days: OR $0.98,95 \%$ CI [0.97, 0.99]) (Table 2).

Figure 2 depicts the predicted probabilities of wearing a face mask for a few covariates. The results demonstrate that overall, the probabilities of mask-wearing increased over time from April until November but the extent to which the probabilities increased over time varied considerably depending on country (ranging from $\sim 1 \%$ increase in Sweden to $50 \%$ increase in the United Kingdom; Fig. 2A). The probability of mask-wearing was also higher among individuals who identify as females (Fig. 2B) or are living in cities (Fig. 2C), while it was lower among those who have gone out to a restaurant/ shopping center (Fig. 2D), socialized outside of the household (Fig. 2E), or attended a large public event (Fig. 2F). The probabilities varied depending on the country.

\section{Discussion}

In this multi-national sample of over 13 million adults from 38 countries, we found considerable heterogeneity in mask use across countries throughout the COVID-19 pandemic, and some cross-country differences were statistically significant even after adjusting for individual- and country-level factors, such as time-varying mask-wearing policy stringency. More specifically, in 13 countries -most of them Latin American or Asian- mask usage prevalence stayed at $70 \%$ or higher throughout our study period, whereas in Denmark, Sweden, and Norway, mask usage has consistently remained below $15 \%$. In most other countries, mask usage was low in April and gradually reached higher levels, although the pace at which this happened varied widely across these countries. A few other countries showed irregular trends over time. See Tables 1 and 3 for more sample characteristics.

These differences suggest that there may be unobserved underlying institutional or cultural phenomena across countries that contribute to the adoption of mask-wearing. Consequently, pre-existing social norms and experiences related to mask-wearing within countries should be taken into consideration when shaping or analyzing mask-related policy guidelines. It is 
Table 2 Weighted logistic regression results on the associations of various individual-level and country-level variables with face mask use ${ }^{a}$

\begin{tabular}{|c|c|c|c|c|}
\hline & \multicolumn{2}{|c|}{$\begin{array}{l}\text { Primary model: } \\
\text { From April } 22 \text { until October } 31\end{array}$} & \multicolumn{2}{|c|}{$\begin{array}{l}\text { Secondary model: } \\
\text { From June } 27 \text { until October } 31\end{array}$} \\
\hline & Odds ratio $(95 \% \mathrm{Cl})$ & $\mathbf{P}$ & Odds ratio $(95 \% \mathrm{Cl})$ & $\mathbf{P}$ \\
\hline \multicolumn{5}{|l|}{ Time (month) } \\
\hline April & ref & & Not available & \\
\hline May & $1.72(1.69,1.75)$ & $<0.001$ & Not available & \\
\hline June & $1.95(1.92,1.99)$ & $<0.001$ & ref & \\
\hline July & $2.01(1.97,2.05)$ & $<0.001$ & $1.14(1.11,1.17)$ & $<0.001$ \\
\hline August & $2.60(2.55,2.65)$ & $<0.001$ & $1.45(1.42,1.48)$ & $<0.001$ \\
\hline September & $2.74(2.69,2.80)$ & $<0.001$ & $1.51(1.48,1.55)$ & $<0.001$ \\
\hline October & $3.40(3.32,3.48)$ & $<0.001$ & $1.90(1.85,1.96)$ & $<0.001$ \\
\hline \multicolumn{5}{|c|}{ COVID-19 test ever taken } \\
\hline No & ref & & ref & \\
\hline Yes & $1.59(1.57,1.61)$ & $<0.001$ & $1.55(1.53,1.58)$ & $<0.001$ \\
\hline \multicolumn{5}{|l|}{ Age } \\
\hline $18-24$ years & ref & & ref & \\
\hline $25-34$ years & $1.22(1.20,1.23)$ & $<0.001$ & $1.16(1.14,1.18)$ & $<0.001$ \\
\hline $35-44$ years & $1.34(1.32,1.36)$ & $<0.001$ & $1.23(1.21,1.26)$ & $<0.001$ \\
\hline $45-54$ years & $1.43(1.41,1.45)$ & $<0.001$ & $1.32(1.29,1.34)$ & $<0.001$ \\
\hline $55-64$ years & $1.42(1.40,1.44)$ & $<0.001$ & $1.28(1.25,1.30)$ & $<0.001$ \\
\hline $65+$ years & $1.47(1.45,1.50)$ & $<0.001$ & $1.27(1.24,1.29)$ & $<0.001$ \\
\hline \multicolumn{5}{|l|}{ Gender } \\
\hline Male/other & ref & & ref & \\
\hline Female & $1.70(1.69,1.71)$ & $<0.001$ & $1.75(1.73,1.77)$ & $<0.001$ \\
\hline \multicolumn{5}{|c|}{ Living in an urban area } \\
\hline No & ref & & ref & \\
\hline Yes & $1.40(1.39,1.41)$ & $<0.001$ & $1.43(1.41,1.44)$ & $<0.001$ \\
\hline \multicolumn{5}{|c|}{ Gone out to work outside in the last $24 \mathrm{~h}$} \\
\hline No & ref & & ref & \\
\hline Yes & $0.98(0.98,0.99)$ & $<0.001$ & $0.98(0.97,0.99)$ & $<0.001$ \\
\hline \multicolumn{5}{|c|}{ Gone out to a market, grocery store or pharmacy in the last $24 \mathrm{~h}$} \\
\hline No & ref & & ref & \\
\hline Yes & $1.07(1.06,1.08)$ & $<0.001$ & $1.01(1.09,1.11)$ & $<0.001$ \\
\hline \multicolumn{5}{|c|}{ Gone out to a restaurant, café, or shopping center in the last $24 \mathrm{~h}$} \\
\hline No & ref & & ref & \\
\hline Yes & $0.77(0.77,0.78)$ & $<0.001$ & $0.76(0.75,0.77)$ & $<0.001$ \\
\hline \multicolumn{5}{|c|}{ Spent time with someone outside their household in the last $24 \mathrm{~h}$} \\
\hline No & ref & & ref & \\
\hline Yes & $0.72(0.72,0.73)$ & $<0.001$ & $0.70(0.69,0.71)$ & $<0.001$ \\
\hline \multicolumn{5}{|c|}{ Attended a public event with more than 10 people in the last $24 \mathrm{~h}$} \\
\hline No & ref & & ref & \\
\hline Yes & $0.45(0.44,0.45)$ & $<0.001$ & $0.46(0.46,0.47)$ & $<0.001$ \\
\hline
\end{tabular}


Table 2 Weighted logistic regression results on the associations of various individual-level and country-level variables with face mask use ${ }^{a}$ (Continued)

\begin{tabular}{|c|c|c|c|c|}
\hline & \multicolumn{2}{|c|}{$\begin{array}{l}\text { Primary model: } \\
\text { From April } 22 \text { until October } 31\end{array}$} & \multicolumn{2}{|c|}{$\begin{array}{l}\text { Secondary model: } \\
\text { From June } 27 \text { until October } 31\end{array}$} \\
\hline & Odds ratio $(95 \% \mathrm{Cl})$ & $\mathbf{P}$ & Odds ratio $(95 \% \mathrm{Cl})$ & $\mathbf{P}$ \\
\hline \multicolumn{5}{|l|}{ Mask policy stringency score } \\
\hline Per 1 standard deviation & $1.58(1.58,1.59)$ & $<0.001$ & $1.50(1.48,1.51)$ & $<0.001$ \\
\hline \multicolumn{5}{|c|}{ Seven day lagged COVID-19 cases } \\
\hline Per 1 standard deviation & $0.93(0.93,0.94)$ & $<0.001$ & $0.98(0.98,0.99)$ & $<0.001$ \\
\hline \multicolumn{5}{|l|}{ Worked in the last 7 days } \\
\hline No & Not available & & ref & \\
\hline Yes & Not available & & $0.98(0.97,0.99)$ & $<0.001$ \\
\hline \multicolumn{5}{|c|}{ Worried about household finances } \\
\hline No & Not available & & ref & \\
\hline Yes & Not available & & $0.88(0.87,0.89)$ & $<0.001$ \\
\hline \multicolumn{5}{|l|}{ Years of education } \\
\hline Per 1 year & Not available & & $1.07(1.07,1.08)$ & $<0.001$ \\
\hline
\end{tabular}

${ }^{a}$ Dependent variable: mask usage (binary), type: Analysis of complex survey design; link function: logit. Model includes fixed effects by country (not shown in Table). Pseudo $R^{2}=0.27$ for the primary model; Pseudo $R^{2}=0.26$ for secondary model.

challenging to compare and contrast our mask use estimates or trends to those from other data sources, since this is, to the best of our knowledge, the first study that describes global longitudinal trends of face maskwearing during the COVID-19 pandemic using samples of this scale. However, we found that the trends of mask use for some countries in our study (e.g., France,
Germany, United Kingdom, and Sweden) are broadly similar to those reported by other online survey platforms such as YouGov's COVID-19 Public Monitor [27].

Our findings also show that certain demographic factors; namely, older age, female gender, urbanicity, and higher education levels are associated with mask use. This is in line with previous studies reporting that age,

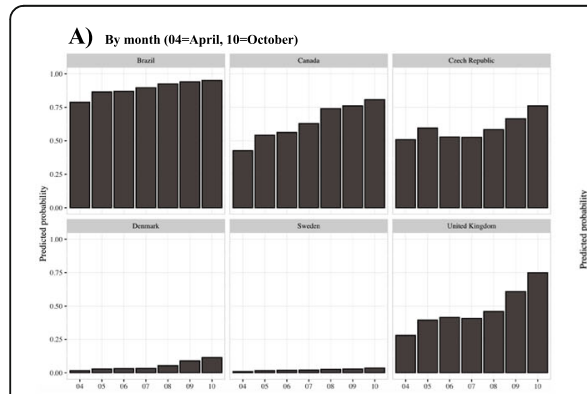

B) By gender (Yes=Female, No=Not Female)

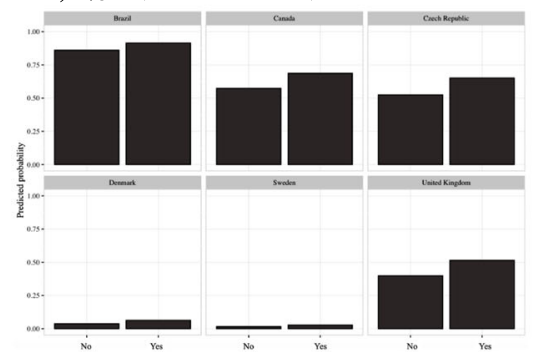

C) By urbanicity (Yes=Urban oo=Not Urban)

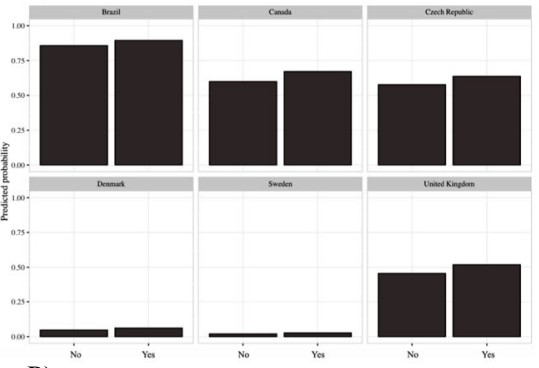

D) By going out to a restaurant, café, or shopping center

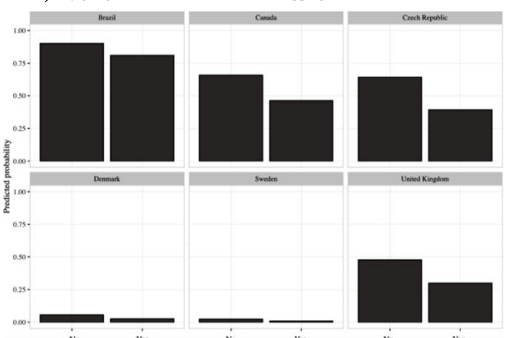

E) By socializing outside the household

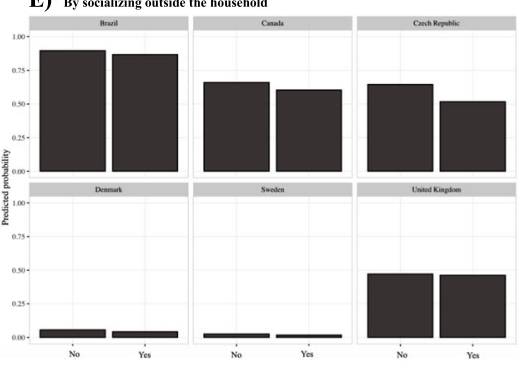

F) By attending a large public event

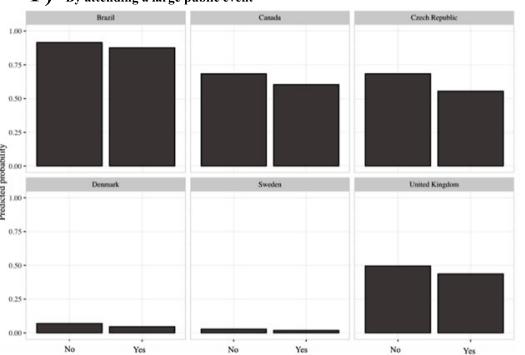

Fig. 2 Predicted probability of face mask usage by individual characteristics for selected countries given various categories of A) month, B) gender, C) urbanicity, D) having gone to a restaurant, café or shopping center, E) having socialized outside of the household, and D) having attended a large public event. Panel 2A) By month (04=April, $10=$ October). Panel 2B) By gender (Yes= Female, No= Not Female). Panel 2C) By urbanicity (Yes = Urban, No = Not Urban). Panel 2D) By going out to a restaurant, café, or shopping center. Panel 2E) By socializing outside the household. Panel 2F) By attending a large public event 
Table 3 Weighted distribution of respondent characteristics among 13,723,810 respondents who reported being in public in the past 7 days and provided complete responses

\begin{tabular}{|c|c|c|c|c|c|c|c|c|c|}
\hline \multirow[b]{2}{*}{ Sex } & \multicolumn{3}{|c|}{$\begin{array}{l}\text { Overall } \\
\text { (Unweighted } N= \\
13,723,810 \text { ) }\end{array}$} & \multicolumn{3}{|c|}{$\begin{array}{l}\text { Mask usage }=1^{a} \\
\text { (Unweighted } N= \\
10,610,836)\end{array}$} & \multicolumn{3}{|c|}{$\begin{array}{l}\text { Mask usage }=0^{b} \\
\text { (Unweighted } N= \\
3,112,974)\end{array}$} \\
\hline & \multicolumn{3}{|l|}{$\%$} & \multicolumn{3}{|l|}{$\%$} & \multicolumn{3}{|l|}{$\%$} \\
\hline Female & \multicolumn{3}{|c|}{43.15} & \multicolumn{3}{|c|}{43.96} & \multicolumn{3}{|c|}{39.03} \\
\hline Male & \multicolumn{3}{|c|}{56.64} & \multicolumn{3}{|c|}{55.85} & \multicolumn{3}{|c|}{60.66} \\
\hline Other & \multicolumn{3}{|l|}{0.20} & \multicolumn{3}{|l|}{0.18} & \multicolumn{3}{|l|}{0.30} \\
\hline Age & \multicolumn{3}{|l|}{$\%$} & \multicolumn{3}{|l|}{$\%$} & \multicolumn{3}{|l|}{$\%$} \\
\hline $18-34$ & \multicolumn{3}{|c|}{14.68} & \multicolumn{3}{|c|}{14.71} & \multicolumn{3}{|c|}{14.52} \\
\hline $25-34$ & \multicolumn{3}{|c|}{26.29} & \multicolumn{3}{|c|}{26.97} & 22.8 & & \\
\hline $35-44$ & 18.76 & & & 18.8 & & & 18.3 & & \\
\hline $45-54$ & 18.3 & & & 18.2 & & & 18.6 & & \\
\hline $55-64$ & 10.70 & & & 10.4 & & & 12.2 & & \\
\hline$>=65$ & 11.26 & & & 10.8 & & & 13.4 & & \\
\hline Current location & $\%$ & & & $\%$ & & & $\%$ & & \\
\hline Urban & 46.37 & & & 44.33 & & & 56.7 & & \\
\hline Non-urban & 53.63 & & & 55.67 & & & 43.2 & & \\
\hline Gone to work outside in the last $24 \mathrm{~h}$ & $\%$ & & & $\%$ & & & $\%$ & & \\
\hline Yes & 36.23 & & & 35.63 & & & 39.2 & & \\
\hline No & 63.76 & & & 64.36 & & & 60.7 & & \\
\hline Gone to a market, grocery store, or pharmacy in the last $24 \mathrm{~h}$ & $\%$ & & & $\%$ & & & $\%$ & & \\
\hline Yes & 65.79 & & & 65.2 & & & 68.58 & & \\
\hline No & 35.96 & & & 34.76 & & & 31.4 & & \\
\hline Gone to a restaurant, café, or shopping center in the last $24 \mathrm{~h}$ & $\%$ & & & $\%$ & & & $\%$ & & \\
\hline Yes & 25.36 & & & 23.8 & & & 33.1 & & \\
\hline No & 74.6 & & & 76.15 & & & 66.8 & & \\
\hline Spent time with a non-same household member in the last $24 \mathrm{~h}$ & $\%$ & & & $\%$ & & & $\%$ & & \\
\hline Yes & 43.16 & & & 40.7 & & & 55.6 & & \\
\hline No & 56.8 & & & 59.2 & & & 44.3 & & \\
\hline Attended a public event with more than 10 people in the last $24 \mathrm{~h}$ & $\%$ & & & $\%$ & & & $\%$ & & \\
\hline Yes & 10.31 & & & 9.65 & & & 17.6 & & \\
\hline No & 89.05 & & & 90.35 & & & 82.38 & & \\
\hline Tested for COVID-19 & $\%$ & & & $\%$ & & & $\%$ & & \\
\hline Yes & 12.92 & & & 13.36 & & & 10.7 & & \\
\hline No & 87.06 & & & 86.6 & & & 89.22 & & \\
\hline Worried about household finances in the next month ${ }^{c}$ & $\%$ & & & $\%$ & & & $\%$ & & \\
\hline Yes & 21.01 & & & 21.35 & & & 17.68 & & \\
\hline No & 78.99 & & & 78.6 & & & 82.3 & & \\
\hline Worked for pay in the last 7 days $^{c}$ & $\%$ & & & $\%$ & & & $\%$ & & \\
\hline Yes & 53.10 & & & 53.8 & & & 58.7 & & \\
\hline No & 46.90 & & & 46.1 & & & 41.2 & & \\
\hline Years of education ${ }^{c}$ & Q1 & Q2 & Q3 & Q1 & Q2 & Q3 & Q1 & Q2 & Q3 \\
\hline & 10 & 14 & 17 & 11 & 15 & 17 & 9 & 13 & 16 \\
\hline
\end{tabular}

aPrimary model (full analytic sample; April 23, 2020 - October 31, 2020)

${ }^{b}$ Secondary model (June 27, 2020 - October 31, 2020)

'Variable only included in the secondary model, fit with the narrower time period in which it was available 
gender, and education are significant predictors of face mask usage in the context of past outbreaks, such as SARS-Cov-1 and H1N1 [10-14]. Moreover, while it is not in the scope of this study to investigate the mechanisms through which age and gender affect mask usage, it has been documented that, in part due to peer effects and social role models, both female and older individuals tend to engage more in health-preventive behaviors, relative to male and younger individuals $[11,28,29]$.

Less previous work has focused on urbanicity and mask wearing. One study conducted in Australia reported that those living in rural areas as opposed to urban areas are more likely to wear a face mask [11]. In contrast, we observed that those living in urban areas are more likely to wear a mask. Notably, the previous study was conducted in the context of an anticipated outbreak scenario, not during an actual global pandemic, and was focused in just one country.

Notably, we found that, even controlling for sociodemographic and country-level factors, social behaviors were differentially associated with wearing a mask. Specifically, social behaviors deemed more optional and risky in the context of the current pandemic, [30] such as going out to large public events, restaurants, cafes, shopping centers, or socializing outside of the household were associated with lower face mask usage. Other behaviors that also take place outdoors but may be less optional, such as going to a market, grocery store, or pharmacy, were associated with higher mask use. These results suggest that those who voluntarily engage in risky social activities during the pandemic are also less likely to wear a mask, which highlights a critical target for public health intervention, as these groups may contribute to higher risks of COVID-19 spread [31]. Finally, our study found that, even controlling for COVID-19 cases, time and country-fixed effects, stricter country-level policies around mask-wearing were associated with higher mask use. Taken together, these two results suggest that more emphasis should be made on designing targeted mask wearing policies in settings where individuals are less likely to do so.

This study has some limitations. First, years of education, financial worry, and employment status were not collected throughout the full field collection period, even though these may be important covariates to examine in association with mask use. To address this, however, we fit a secondary model that did include these three variables using the narrower time period during which they were collected, and found that the results for most associations remained very similar. Second, given our nonexperimental study design, we cannot infer any causation from our findings.

Despite these limitations, there are several strengths to this study. Our analysis leveraged the largest ongoing, data collection related to COVID-19 symptoms and behaviors, which allowed us to examine and compare face mask usage trends across many countries and include a long time period spanning 7 months. We also simultaneously examined individual and country-level characteristics in our models, which allowed us to more adequately model the individual decision to wear a mask. Lastly, while the Facebook user base varies in its composition by country, we do not expect the trends to be affected, for there are no reported large shifts in the Facebook user base within countries during the study period.

In sum, our findings provide a better understanding of who are more or less likely to wear face masks in public during an outbreak and suggest that public health messaging should better target individuals who do not wear face masks in public as frequently. This has important implications for health prevention policies and messaging in the context of the ongoing and future public health emergencies, as they highlight important differences in mask usage between countries, as well as the importance of better targeting specific subpopulations when designing such policies and messaging campaigns.

\section{Conclusions}

This study is the first to examine mask-wearing throughout the COVID-19 pandemic worldwide. In summary, it shows that various sociodemographic factors, such as older age, female gender, higher education, and urbanicity, are associated with higher face mask usage, while more risky social behaviors, such as going out to a large public event, restaurant, shopping center, and socializing outside of the household are associated with lower mask use. In addition, stronger face mask-related policies are associated with higher mask usage. Taken together with existing evidence regarding the effectiveness of mask usage, our findings have important implications for health prevention policies and messaging in the context of the ongoing and future public health emergencies, as they highlight the importance of better targeting specific populations and behaviors when designing policies and messaging campaigns.

\section{Supplementary Information}

The online version contains supplementary material available at https://doi. org/10.1186/s12889-021-12175-9.

\section{Additional file 1.}

\section{Acknowledgements}

We are grateful for the support from Kathleen Stewart, Junchuan Fan, Brian Kim in creating the data pipeline, Stanley Presser Alyssa Bilinski, and Josh Salomon, in supporting the questionnaire development. The following Facebook employees were also heavily involved in this project and we are extremely thankful for their support: Tali Alterman Barash, Neta Barkay, Roee Eliat, Andres Garcia, Tal Galili, Andi Gros, Daniel Haimovich, Ahmed Isa, Alex Kaess, Faisal Karim, Ofir Eretz Kedosha, Shelly Matskel, Roee Melamed, Amey Patankar, Irit Rutenberg, Tal Salmona, Tal Sarig, David Vannette. At the 
University of Maryland we also thank Katie McKeon and Joseph M. Smith for their fast turnarounds on important legal and ethical steps.

\section{Statement on guidelines}

All procedures were performed in accordance with relevant guidelines

\section{Authors' contributions}

EBG and THC processed, analyzed, and summarized the survey and UMD CITS datasets, and used them to estimate the models reported in the study. $E A S, E B G, T H C$, and EK were major contributors in writing the manuscript. CC and FK designed and lead the overall data collection, SL, KM, XD, SC and AB designed the survey instrument, and AG prepared the data for the analysis pipeline. CK helped with validating the survey data. All authors read and approved the final manuscript.

\section{Funding}

This work was supported in part by the National Science Foundation NSFRAPID award "Evaluating the Impact of COVID-19 on Labor Market, Social, and Mental Health Outcomes" (Bennett, de Bruin, Kreuter, Stuart, Thrul), and in part by Facebook for survey data collection and support time for data analysis.

\section{Availability of data and materials}

The survey data that support the findings of this study are available and publicly available on the University of Maryland's website (https://covidmap. umd.edu/api.html). This website also has the survey questionnaire and detailed documentation of the data that are aggregated and uploaded daily. Individual-level data, which includes daily files with the survey variables and weights, are available for academic and nonprofit researchers upon request to the University of Maryland and Facebook. For instructions on how to submit an access form, please visit the website at https://covidmap.umd.edu/. Other data used in this study, such as those from Johns Hopkins University's COVID-19 data repository and University of Oxford's COVID-19 dataset are also publicly available online at https://github.com/CSSEGISandData/COVID-1 9, and https://www.bsg.ox.ac.uk/research/research-projects/coronavirusgovernment-response-tracker, respectively.

\section{Declarations}

\section{Ethics approval and consent to participate}

Not applicable. All authors confirm that: 1) no medical research involving human subjects took part in this study, 2) none of the data that support the findings of this study included any identifiable human material or data.

\section{Consent for publication}

Not applicable.

\section{Competing interests}

Frauke Kreuter consulted with Facebook from August 2018 - June 2020. Esther Kim, Sarah LaRocca, and Katherine Morris are employed at Facebook and assisted with the interpretation of the results and editing of the manuscript. All other authors declare that they have no competing interests.

\section{Author details}

'Department of Mental Health, Johns Hopkins Bloomberg School of Public Health, 615 N. Wolfe St. W1033, Baltimore, MD 21205, USA. ${ }^{2}$ Department of Biostatistics, Johns Hopkins Bloomberg School of Public Health, 615 N. Wolfe St. W1033, Baltimore, MD 21205, USA. ${ }^{3}$ Facebook Research, Menlo Park, California, USA. ${ }^{4}$ Joint Program in Survey Methodology, University of Maryland College Park, College Park, MD, USA. ${ }^{5}$ University of Mannheim, Mannheim, Germany. ${ }^{6}$ Department of Statistics, Ludwig Maximilians University, Munich, Germany. ${ }^{7}$ Institute for Employment Research, Nuremberg, Germany.

Received: 14 January 2021 Accepted: 1 November 2021

Published online: 15 November 2021

\section{References}

1. Ueki H, Furusawa Y, Iwatsuki-Horimoto K, et al. Effectiveness of Face Masks in Preventing Airborne Transmission of SARS-CoV-2. mSphere. 2020:5(5):2-6. https://doi.org/10.1128/msphere.00637-20.
2. Taminato M, Mizusaki-Imoto A, Saconato H, et al. Homemade cloth face masks as a barrier against respiratory droplets - Systematic review. ACTA Paul Enferm. 2020;33:1-11. https://doi.org/10.37689/ACTA-APE/2020AR0103.

3. Lyu W, Wehby GL. Community use of face masks and COVID-19: evidence from a natural experiment of state mandates in the US. Health Aff (Millwood). 2020;39(8):1419-25. https://doi.org/10.1377/hlthaff.2020.00818.

4. Li T, Liu Y, Li M, Qian X, Dai SY. Mask or no mask for COVID-19: A public health and market study. PLoS One. 2020;15(8 August):1-17. https://doi. org/10.1371/journal.pone.0237691.

5. Derek K. Chu, Elie a Akl, Stephanie Duda, Karla solo, Sally Yaacoub HJS. Physical distancing, face masks, and eye protection to prevent person-toperson transmission of SARS-COV-2 and COVID-19: a systematic review and meta-analysis Derek K Chu, Elie a Akl, Stephanie Duda, Karla solo, Sally Yaacoub, Holger J Schünemann, on beha. Lancet. 2020;395(June):1973-87. https://doi.org/10.1016/\%0AS0140-6736(20)31142-9.

6. Rader B, White L, Burns M, et al. Mask Wearing and Control of SARS-CoV-2 Transmission in the United States. medRxiv. Published online. 2020.

7. Lerner AM, Folkers GK, Fauci AS. Preventing the spread of SARS-CoV-2 with masks and other "low-tech" interventions. JAMA. 2020;20892(19):4-5. https:// doi.org/10.1001/jama.2020.21946.

8. Sun CX, He B, Mu D, Li PL, Zhao HT, Li ZL, et al. Public awareness and mask usage during the COVID-19 epidemic: a survey by China CDC new media. Biomed Environ Sci. 2020;33(8):639-45. https://doi.org/10.3967/bes2020.085.

9. Fisher KA, Barile JP, Guerin RJ, et al. Factors Associated with Cloth Face Covering Use Among Adults During the COVID-19 Pandemic - United States, April and May 2020. MMWR Morb Mortal Wkly Rep. 2020;69(28):9337. https://doi.org/10.15585/mmwr.mm6928e3.

10. Sim SW, Moey KSP, Tan NC. The use of facemasks to prevent respiratory infection: A literature review in the context of the Health Belief Model. Singap Med J. 2014;55(3):160-7. https://doi.org/10.11622/smedj.2014037.

11. Taylor M, Raphael, Barr, Agho, Stevens, Jorm. Public health measures during an anticipated influenza pandemic: Factors influencing willingness to comply. Risk Manag Healthc Policy Published online. 2009:9. https://doi. org/10.2147/rmhp.s4810.

12. Condon BJ, Sinha T. Who is that masked person: the use of face masks on Mexico City public transportation during the influenza a ( $\mathrm{H} 1 \mathrm{~N} 1)$ outbreak. Health Policy (New York). 2010;95(1):50-6. https://doi.org/10.1016/j.hea Ithpol.2009.11.009.

13. Lau JTF, Griffiths S, Choi K. Chow, Lin C. prevalence of preventive behaviors and associated factors during early phase of the H1N1 influenza epidemic. Am J Infect Control. 2010;38(5):374-80. https://doi.org/10.1016/j.ajic.2010.03. 002.

14. Tang CSK, Wong CY. Factors influencing the wearing of facemasks to prevent the severe acute respiratory syndrome among adult Chinese in Hong Kong. Prev Med (Baltim). 2004;39(6):1187-93. https://doi.org/10.1016/j. ypmed.2004.04.032.

15. Institute of Medicine (US) Committee on Communication for Behavior Change in the 21st Century: Improving the Health of Diverse Populations. In: Speaking of Health: Assessing Health Communication Strategies for Diverse Populations, vol. 3. Washington (DC): National Academies Press (US); 2002. Health Communication Campaigns Exemplar. Available from: https:// www.ncbi.nlm.nih.gov/books/NBK222234/.

16. Roundtable on Population Health Improvement; Board on Population Health and Public Health Practice; Institute of Medicine. Communicating to Advance the Public's Health: Workshop Summary, vol. 5. Washington (DC): National Academies Press (US); 2015. Effective Messaging Strategies: A Review of the Evidence. Available from: https://www.ncbin.nlm.nih.gov/ books/NBK338333/

17. Kreuter F, et al. Partnering with Facebook on a university-based rapid turnaround global survey. Surv Res Methods. 2020;14(2):159-63. https://doi.org/1 0.18148/srm/2020.v14i2.7761

18. Delphi Epidata API: COVID symptom survey. Published 2020. Accessed November 11, 2020. https://cmu-delphi.github.io/delphi-epidata/symptomsurvey/

19. University of Maryland COVID-19 World Survey Data. 2020. Accessed November 11, 2020. https://covidmap.umd.edu/api.html

20. Barkay N, Cobb C, Eilat R, et al. Weights and methodology brief for the COVID-19 Symptom Survey by University of Maryland and Carnegie Mellon University, in partnership with Facebook. arXiv Published online. 2020.

21. GADM Maps and data. 2020. Accessed November 11, 2020. https://gadm. org/ 
22. FB. Facebook Data Policy. Published 2020. Accessed November 11, 2020 https://www.facebook.com/policy.php

23. UN. United Nations Population Division. World population prospects 2019, standard projections. Published 2020. https://population.un.org/wpp/ Download/Standard/CSV/

24. OECD. OECD: Our Global Reach. Published 2020. Accessed November 11, 2020. https://www.oecd.org/about/members-and-partners/

25. Max Roser, Hannah Ritchie EO-O and JH. Coronavirus Pandemic (COVID-19). Published online 2020. Accessed November 11, 2020. https://ourworldinda ta.org/policy-responses-covid

26. JHU. Johns Hopkins University CSSE GIS and Data. Published 2020. Accessed November 11, 2020. https://github.com/CSSEGISandData

27. YouGov. COVID-19 Public Monitor. Published 2020. Accessed November 11, 2020. https://yougov.co.uk/covid-19

28. Liang W, Shediac-Rizkallah MC, Celentano DD, Rohde C. A population-based study of age and gender differences in patterns of healthrelated behaviors. Am J Prev Med. 1999;17(1):8-17. https://doi.org/10.1016/S0749-3797(99)0004 $0-9$

29. Ek S. Gender differences in health information behaviour: a Finnish population-based survey. Health Promot Int. 2015;30(3):736-45. https://doi. org/10.1093/heapro/dat063.

30. WHO. Coronavirus disease (COVID-19) advice for the public. Published 2020 Accessed November 11, 2020. https://www.who.int/emergencies/diseases/ novel-coronavirus-2019/advice-for-public

31. CDC. Daily Activities \& Going Out. Published 2020. Accessed November 11 2020. https://www.cdc.gov/coronavirus/2019-ncov/daily-life-coping/goingout.html

\section{Publisher's Note}

Springer Nature remains neutral with regard to jurisdictional claims in published maps and institutional affiliations.

Ready to submit your research? Choose BMC and benefit from:

- fast, convenient online submission

- thorough peer review by experienced researchers in your field

- rapid publication on acceptance

- support for research data, including large and complex data types

- gold Open Access which fosters wider collaboration and increased citations

- maximum visibility for your research: over $100 \mathrm{M}$ website views per year

At $\mathrm{BMC}$, research is always in progress.

Learn more biomedcentral.com/submissions 